\title{
ДИФФРАКЦИЯ ОДИНОЧНЫХ ПООЧЕРЁДНО ЛЕТЯЩИХ ЭЛЕКТРОНОВ
}

В квантовой механике огромную роль играет представление о волновых свойствах, присущих индивидуальным частицам (электронам, нейтронам и т. д.). В основе этих представлений лежат опыты по диффракцик частиц на различных объектах. Однако до сих пор все эксперименты производились $\mathrm{c}$ интенсивными пудками частиц, и лишь благодаря тому, что в них была в широких пределах показана независимость диффракционной картины от интенсивности пучка, можно было, экстраполируя әто обстоятельство до одиночных частиц, приписывать им волновые свойства, т. е. утверждать, что диффракционная картина не является результатом каких-то коллективных взаимодействий частиц пучка с диффрагирующим обьектом. Поэтому в курсах квантовой механики рассматривается вмысленный эксперимент» по днффракции одиночных поочерёдно летящих әлектронов. Понятно, что практическое осуществление такого эксперимента имеет очень важное принципиальное значение.

Недавно такой опыт был произведён Л. Биберманом, Н. Сушкиным и В. Фабрикантом в Московском Энергетическом институте им. Молотова 1. Для наблюдения диффракции они воспользовались магнитным электронным микроскопом просвечивающего типа $(9 M-100)^{2}$, в котором был сделан ряд конструктивных изменений: удалены полюсные наконечники проекционной линзы с их держателем, вынут промежуточный экран и два внутренних пермаллоевых әкрана объективного тубуса. Кроме того, была введена дополнительная диафрагма над диффрагирующим объектом, установлен фарадеев цилиндр, соединённый с зеркальным гальванометром чувствительностью $2,7 \cdot 10^{-11}$ ампер на деление и добавлено приспособление, позволяюшее перемешать фотопластинку без нарушения вакуума, благодаря чему на одной и той же пластинке можно было получать до 28 снимков.

Для измерения интенсивности чрезвычайно слабого пучка электронов, лежащей далеко за пределами чувствительностн гальванометра, был использован следующий метод. Вначале создавался пучок электронов $c$ йтенсивностью, достаточной для измерения гальванометром; пучок улавливался фарадеевым цилиндром, и по отбросу зайчика гальванометра определялась интенсивность. После этого фарадеев цилиндр отводился в сторону, а падающий на пластинку пучок с помощью проекционной линзы развёртывался в серию пятен с постепенно увеличиваюшимся (до 10 c.M) диаметром. Фотометрическая проверка показала, что плотность почернения одинакова в пределах каждого пятна, поэтому плотность электронов для каждого пятна определялась как частное от деления известной интенсивности пучка на плошадь пятна. По ннтенсивности почернения 
и плотности электронов строилась кривая почернення для каждой фотопластинки, позволяющая определять интенсивности пучка, по крайней мере на пять порядков меньшие предела чувствительности гальванометра. После этого интенсивность пучка резко уменьпалась, и при выключенных линзах фнксировался след пучка на пластинке, по которому и определялась интенсивность слабого пучка электронов. Затем на пути пучка помешался диффрагирующий объект - кристаллики окиси магния, нанесённые на коллодионную плёнку, с помощью которых получали диффракционную картину. Для проверки постоянства интенсивности диффраГирующий объект после әкспозиции убирался, и на пластинке снова фиксировался след пучка. Диффракционые картины в сильных пуцках получались. обы ным путём на фотопластинках со значительно меньпей qувствительностью.

Таким образом, были полудены диффракционные картины от пучков, отличавтихся по интенсивности почти на семь порядков. Они оказались совершенно тождественными. Измерение интенсивности слабого пучка дало знапение $4,2 \cdot 10^{\mathrm{s}}$ электрона в секунду. Отсюда среднее время между двумя прохождениями электронов в приборе равно $2,4 \cdot 10^{-4}$ сек. Так как электроны ускорялись до энергии в $72 \mathrm{keV}$, то каждый из них проходил весь путь в приборе за $8,5 \cdot 10^{-9}$ сек. т. е. время двнжения было в $3 \cdot 10^{4}$ раз меньше интервала между двумя попаданиями электронов в пластинку. Иными словами, картина движения электронов в приборе при получении диффракционной картины от слабого пучка была такова: электрон проходил прибор за $8,5 \cdot 10^{-9}$ сек, затем в течение в 30000 раз (!) большего интервала времени (в среднем) прибор оставался пуст, и лишь после этого через него проходил новый электрон. Оревидно, что при таком огромном пнтервале времени между последовательными прохождениями вероятность одновременного прохождения хотя бы двух электронов совершенно ничтожна.

Нет сомнения, что этот опыт в ближайшее время войдёт во все курсы квантовой механики.

B. $\pi$.

\section{ЦИТИРОВАННАЯ ЛИТЕРАТУРА}

1. Л. Биб ер ман, Н. С ушкин и В. Фабрикант, ДАН CССР, LXVI, 185 (1949).

2. Н. С у ши к н, Әлектронный микроскоп, Гостехиздат, 1949. 